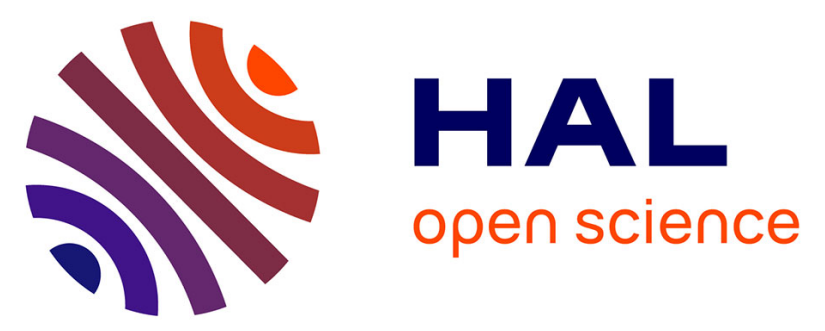

\title{
Developmental changes in interkinetic nuclear migration dynamics with respect to cell-cycle progression in the mouse cerebral cortex ventricular zone
}

\author{
Julie Fousse, Elodie Gautier, Dorothée Patti, Colette Dehay
}

\section{- To cite this version:}

Julie Fousse, Elodie Gautier, Dorothée Patti, Colette Dehay. Developmental changes in interkinetic nuclear migration dynamics with respect to cell-cycle progression in the mouse cerebral cortex ventricular zone. Journal of Comparative Neurology, 2019, 527 (10), pp.1545-1557. 10.1002/cne.24641 . hal-02349447

\section{HAL Id: hal-02349447 \\ https://hal.science/hal-02349447}

Submitted on 14 Dec 2020

HAL is a multi-disciplinary open access archive for the deposit and dissemination of scientific research documents, whether they are published or not. The documents may come from teaching and research institutions in France or abroad, or from public or private research centers.
L'archive ouverte pluridisciplinaire $\mathbf{H A L}$, est destinée au dépôt et à la diffusion de documents scientifiques de niveau recherche, publiés ou non, émanant des établissements d'enseignement et de recherche français ou étrangers, des laboratoires publics ou privés. 
Fousse J, Gautier E, Patti D, Dehay C. Developmental changes in interkinetic nuclear migration dynamics with respect to cell-cycle progression in the mouse cerebral cortex ventricular zone. J Comp Neurol. 2019;1-13.

https://doi.org/10.1002/cne.24641

\title{
Developmental changes in interkinetic nuclear migration dynamics with respect to cell-cycle progression in the mouse cerebral cortex ventricular zone
}

\author{
Julie Fousse, Elodie Gautier, Dorothée Patti, Colette Dehay
}

Univ Lyon, Université Claude Bernard Lyon 1, Inserm, Stem Cell and Brain Research Institute U1208, Bron, France

Correspondence : Colette Dehay, colette.dehay@inserm.fr

\begin{abstract}
We have examined the relationship between interkinetic nuclear migration (INM) and cell-cycle progression of apical progenitors in the ventricular zone (VZ) at different stages of mouse cerebral corticogenesis. We report stage-specific changes in INM due to a significant alteration of the nuclear apical movement dynamics with respect to cell-cycle phases. While at early stages, the apical nuclear movement corresponds to the G2 phase, cell-cycle phase specific immunostaining and real-time imaging of PCNA expressing apical progenitors revealed that at midcorticogenesis, the nuclear apical movement is initiated well before the entry into G2, during S phase. We observed that the S phase and G2 phase segments of the nuclear apical movement exhibit different velocities. Experimental shortening of cellcycle duration via cyclin E overexpression in APs at midcorticogenesis leads to congruent INM behavior changes. This suggests that INM dynamics are under cell-cycle related constraints.
\end{abstract}

\section{INTRODUCTION}

The early telencephalon arises from the neuroepithelium (NE), which is exclusively populated by progenitor cells (Götz \& Barde, 2005; Miyata, 2008). Each progenitor cell exhibits a bipolar morphology with apical and basal processes that contact the ventricular and pial surfaces, respectively. Mitosis in the proliferating vertebrate NE occurs at the apical end of the NE. The newborn progenitor cells at the apical surface then move toward the basal end of the NE during G1 phase of the cell cycle. After completing $\mathrm{S}$ phase in the basal portion of the NE, the progenitor cells migrate to the apical surface, where they undergo division. This stereotyped nuclear movement during the cell-cycle has been coined as interkinetic nuclear migration or INM (Sauer, 1935) reviewed in (Taverna \& Huttner, 2010).

As brain development proceeds, the anterior neuroepithelium thickens and morphs into a pseudostratified germinal zone, the ventricular zone (VZ) which houses cortical progenitors identified as radial glial cells bearing apical and basal processes (Malatesta, Hartfuss, \& Gotz, 2000; Noctor, Flint, Weissman, Dammerman, \& Kriegstein, 2001; Rakic, 1972), recently defined as apical progenitors (APs) (Attardo, Calegari, Haubensak, Wilsch-Brauninger, \& Huttner, 2008). In situ and real time imaging observations show that the APs of the VZ undergo INM (Baffet, Hu, \& Vallee, 2015; Carabalona, Hu, \& Vallee, 2016; Okamoto, Shinoda, Kawaue, Nagasaka, \& Miyata, 2014; Strzyz et al., 2015). 
INM is a conserved feature that occurs in a variety of tissues and species (Bort, Signore, Tremblay, Martinez Barbera, \& Zaret, 2006; Grosse et al., 2011; Langman \& Nelson, 1968; Malatesta et al., 2000; Meyer, Ikmi, \& Gibson, 2011; Noctor et al., 2001; Norden, Young, Link, \& Harris, 2009; Yamada et al., 2013). It is an intrinsic and robust mechanism, characteristic of pseudostratified epithelia (Lee \& Norden, 2013) which is observed as the cells self-organize in an epithelium surrounding a cavity in 3D organoids (Carroll et al., 2017; Kadoshima et al., 2013; Lancaster et al., 2013; Nasu et al., 2012).

Significant advances have been recently made in the identification of the molecular players driving the basal-directed and apical-directed movements. It has been established that microtubules associated dynein is involved in the apical nuclear migration to carry the nucleus at the apical surface (Baffet et al., 2015; Kosodo et al., 2011; Tsai, Chen, Kriegstein, \& Vallee, 2005) while forces behind the basal directed movement are still under debate. Actin (Schenk, Wilsch-Brauninger, Calegari, \& Huttner, 2009) and microtubules associated kinesin (Tsai, Lian, Kemal, Kriegstein, \& Vallee, 2010) have been proposed, in addition to passive forces generated by the displacement of nuclei moving apically (Kosodo et al., 2011).

Numerous observations point to a coupling between cell-cycle progression and INM in brain and retina neuroepithelia (Kosodo et al., 2011; Sargeant, Day, Miller, \& Steel, 2008; Tsai et al., 2005), where progenitors show different cell-cycle rates. In the developing cortex, the APs undergo extensive proliferation and it has been shown that their cell-cycle duration increases from early to late stages of corticogenesis, ranging from $8 \mathrm{hr}$ at E11 to $18 \mathrm{hr}$ at E16 (Calegari, Haubensak, Haffner, \& Huttner, 2005; Caviness, Takahashi, \& Nowakowski, 1995; Polleux, Dehay, Moraillon, \& Kennedy, 1997). This lengthening of the cell-cycle is accompanied by marked variations in the duration of G1 and S phase which have been reported to lengthen and shorten, respectively (Arai et al., 2011; Calegari et al., 2005) while the G2 and M phases appear less variable. Concomitantly, there is a thickening of the VZ, which imposes physical constraints including cell crowding (Miyata, Okamoto, Shinoda, \& Kawaguchi, 2015) as well as increased basal and apical INM trajectories for APs nuclei. This raises the possibility that the developmental increase in VZ thickness and changes in cell-cycle progression might affect APs INM dynamics.

Here we examine how cell-cycle kinetic changes and INM dynamics in APs are integrated during mouse corticogenesis. We focused on three stages spanning the bulk of corticogenesis: E12, E14, and E16 and implemented two complementary approaches to characterize in parallel cell-cycle kinetics and INM, both at the population level and at the single cell level. At the population level, we developed a high resolution immunolabeling strategy that unambiguously identifies the four distinct cell-cycle phases, based on the intracellular pattern of the combined expression of Ki-67 and PCNA (Kill, 1996; Leonhardt et al., 2000; Starborg, Gell, Brundell, \& Hoog, 1996). While PCNA is a marker of the replication machinery (S phase), Ki-67 is located in the nucleoplasm during G1 phase and in the nucleolus during S and G2 phases (Kill, 1996; Leonhardt et al., 2000). At the single cell level, real time imaging of PCNA-GFP expressing APs on organotypic slices provided the detailed timing of the progression of APs from S to G2 phase during the apical directed movement.

We show that the relationship between cell-cycle phases and INM dynamics changes during development. At early stages (E12) the G1 phase was found to correspond to the basal directed movement, S phase to the stationary stage at the basal border, G2 to the apical directed movement and $\mathrm{M}$ to the stationary stage at the apical border, in agreement with the classical textbook description of INM (Hayes \& Nowakowski, 2000; Sauer \& Walker, 1959). By contrast, at later stages, we observed changes in the relationship between G2 phase and apical nuclear movement. Specifically, at E14 and E16- when APs exhibit a shorter G1 and a longer S phase ([Arai et al., 2011], present data)-APs nuclei initiate apical directed movement while they are still in S phase, prior to entering $\mathrm{G} 2$ phase. These nonclassical INM dynamics, suggest the occurrence of stage-specific, cell-cycle correlated control mechanisms of INM. We explored the impact of cell-cycle on INM dynamics by experimental shortening the cell-cycle at midcorticogenesis. Targeted overexpression of Cyclin E at E16 induces 
alteration of the INM behavior, reminiscent to that observed at E12 with respect to the apical movement - which corresponds strictly to the G2 phase. These developmental, cell-cycle related differences in INM dynamics are discussed in light of interspecies comparison and evolutionary perspective.

\section{MATERIAL AND METHODS}

\subsection{Animals}

Experiments were performed in OF1 pregnant females (Charles River, Lyon, France IMSR Cat\# CRL:612, RRID:IMSR_CRL:612). E0.5 is the day of vaginal plug detection. Surgical procedures and animal experimentation were in accordance with European requirements 2010/63/ UE. The protocol C2EA42-12-11-0402-003 has been approved by the Animal Care and Use Committee CELYNE (C2EA \#42).

\subsection{Cell lines}

Mouse 3T6 fibroblasts were obtained from Pierre Savatier (Université Lyon 1, Inserm, Stem Cell and Brain Research Institute U1208, INRA USC 1361, 69500 Bron, France). Cells were cultures in DMEM (Invitrogen Villebon sur Yvette, France, 41,966) supplemented with 5\% FBS (HyClone, Thermo Fisher Scientific, Rockford, IL, USA) medium.

\subsection{Flow cytometry}

Mouse 3T6 fibroblasts were fixed with cold $70^{\circ}$ ethanol then rinsed with phosphate buffer saline (PBS) before labeling with propidium iodide (Thermo Fisher Scientific, Rockford, IL, USA, P1304MP) and RNA degradation with RNAse (PureLink ${ }^{\text {TM }}$ RNase A [20 mg/mL], Invitrogen, 12,091,039). Cells were analyzed using a FACS LSR II (BD Biosciences, Le Pont de Claix, France) equipped with 355, 488, and $561 \mathrm{nM}$ lasers. Data were acquired with DiVa software and analyzed using FlowJo software (http://www.flowjo.com/, RRID:SCR_008520).

\subsection{Brain cryosection}

Embryonic brains were dissected in cold PBS. Brains were fixed by immersion in cold buffered $2 \%$ paraformaldehyde at $4^{\circ} \mathrm{C}$ for $2 \mathrm{hr}$. Cryoprotection was performed by immersion in $10 \%$ sucrose then in $20 \%$ sucrose supplemented with $0.1 \%$ sodium azide. Brains were embedded with Tissue Tek (Sakura Finetek, Zoeterwoude, NL) and $20 \mu \mathrm{m}$ thick coronal sections were performed with a cryostat (Microm HM500, Thermo Fisher Scientific, Rockford, IL, USA) at $-18^{\circ} \mathrm{C}$. Slices were mounted on superfrost glass slides (Superfrost Plus, Thermo Fisher Scientific, Rockford, IL, USA) and stored at $-20^{\circ} \mathrm{C}$.

\subsection{Antibody characterization}

All antibodies used are commercially available and have been previously validated (Supporting Information Table S1).

The anti GFP (Thermo Fisher Scientific, Rockford, IL, USA, catalog \# A10262, RRID:AB_2534023) is a polyclonal antibody against GFP, produced by immunization of chicken with the GFP protein, directly isolated from the jellyfish Aequorea Victoria. The GFP antibody was characterized via immunolabeling on electroporated mouse cortex following retrieval during $10 \mathrm{~min}$ at $95^{\circ} \mathrm{C}$ (see Supporting Information Figure S1).

The anti-PCNA, clone PC10 (DAKO, Agilent, Santa Clara, CA, USA, catalog \# M0879, RRID:AB_2160651) is a monoclonal antibody, produced by immunization of mice with the PCNA protein. The immunogen was obtained from purification of pC2T construct, the rat cDNA for PCNA was cloned into expression vectors (Waseem \& Lane, 1990). PCNA antibody was characterized via western blot in hela cells as well as yeast and insect extracts, via immunoprecipitation of PCNA from extract of CV-1 cells, via staining of CV-1 monkey kidney epithelial cells and human tonsil (Waseem 
\& Lane, 1990). The epitope of this clone is located in the amino acid sequence 111-125 (Roos et al., 1993). The pattern of expression observed in this study corresponds to that described in mouse myoblasts (Leonhardt et al., 2000).

The anti-Ki-67, clone SP6 (Thermo Fisher Scientific, Rockford, IL, USA, catalog \# MA5-14520, RRID:AB 10979488) is a monoclonal antibody, produced by immunization of rabbit with the Cterminal part of Ki-67. The immunogen is a synthetic peptide derived from human Ki-67 protein. The pattern of expression observed in this study follows the one described in human dermal fibroblasts (Kill, 1996) and in mouse Swiss-3 T3 fibroblasts (Starborg et al., 1996). The SP6 epitope is the same as that recognized by MIB1, another antiKi-67 clone (Acs et al., 2017; Dowsett et al., 2011; Zabaglo et al., 2010). The epitopes of these Ki-67 antibodies are coded by a conserved motif of 66 bp (Schluter et al., 1993), constituted of the repeated amino acid sequence FKELF (Kubbutat et al., 1994). In the present study, Ki-67 immunolabeling was exclusively observed in progenitor cells and was absent from postmitotic cells.

We used the following secondary antibodies: a Goat antiChicken $\operatorname{IgY}(\mathrm{H}+\mathrm{L})$ Secondary Antibody, Alexa Fluor 488 (1:1000, Thermo Fisher Scientific, Rockford, IL, USA, catalog \# A-11039, RRID: AB_2534096), a Goat antiMouse IgG (H + L) Cross-Adsorbed Secondary Antibody, Alexa Fluor 647 (1:800, Thermo Fisher Scientific, Rockford, IL, USA, catalog \# A-21235, RRID:AB 2535804) Goat antiRabbit IgG $(\mathrm{H}+\mathrm{L})$ Cross-Adsorbed Secondary Antibody, Alexa Fluor 555 (1:800, Thermo Fisher Scientific, Rockford, IL, USA, catalog \# A21428, RRID:AB_2535849).

\subsection{Immunochemistry}

3 T6 fibroblasts were fixed in cold buffered $2 \%$ paraformaldehyde at $4{ }^{\circ} \mathrm{C}$ for $30 \mathrm{~min}$, then rinsed three times (10 min each) in Tris-Buffer Saline (TBS) and postfixed in cold $70^{\circ}$ ethanol for $20 \mathrm{~min}$ at RT. Permeabilization was performed using Triton $0.5 \%$ in TBS (three times 10 min each) before saturation for 30 min using a mix of TBS and $10 \%$ of Normal Goat Serum (NGS; Thermo Fisher Scientific, Rockford, IL, USA).

Brains sections were defrosted at room temperature (RT) for half an hour, then hydrated in TBS. Retrieval was performed during $10 \mathrm{~min}$ at $95^{\circ} \mathrm{C}$ using a $10 \%$ Antigen-retrieval solution (DAKO, Agilent, Santa Clara, CA, USA, \#S1699). Brains sections were rinsed three times (10 minutes each) in TBS before they were saturated using a mix of TBS and 10\% of NGS (Thermo Fisher Scientific, Rockford, IL, USA).

After being rinsed $10 \mathrm{~min}$ in TBS, primary antibodies were co-incubated with antibody diluent solution (DAKO, Agilent, Santa Clara, CA, USA) overnight. Brains sections/fibroblasts were rinsed three times in TBS, secondary antibodies were co-incubated with antibody diluent solution (DAKO, Agilent, Santa Clara, CA, USA) for $1 \mathrm{hr}$ at RT. Brains sections/fibroblasts were rinsed three times (10 min each) in TBS before nuclear staining using DAPI (Invitrogen, 1/4000 in TBS) for 10 min at RT. Mounting was performed in Fluoromount G (Southern Biotech, Cliniscience, Nanterre, France).

\subsection{Plasmids}

Massive electroporations were made with pCAGGS-IRES-GFP plasmid provided by J. Briscoe (National Institute for Medical Research, London, UK) via Laurent Nguyen (University of Liège, Belgium) (Nguyen et al., 2006). pCAGGS-IRES-GFP $(0.8 \mu \mathrm{g} / \mu \mathrm{L}$ concentration $)$ was coelectroporated with an empty pHpCAG or a pHpCAG-hCyclE (Pilaz et al., 2009) plasmid at $1.2 \mu \mathrm{g} / \mu \mathrm{L}$ concentration for overexpression Cyclin E experiments. Clonal electroporations were made with a pFlox-pA-EGFP plasmid and a pCX-Cre plasmid provided by Xavier Morin ([Morin, Jaouen, \& Durbec, 2007]; IBENS, France). These plasmids were coelectroporated with an empty pHpCAG or a pHpCAGhCyclE (Pilaz et al., 2009) at $0.5 \mu \mathrm{g} / \mu \mathrm{L}$ concentration combined with a pFlox-pA-EGFP plasmid at $0.5 \mu \mathrm{g} / \mu \mathrm{L}$ concentration and a pCX-Cre plasmid at $0.0002 \mu \mathrm{g} / \mu \mathrm{L}$ concentration for overexpression of Cyclin $\mathrm{E}$ 
experiments. The GFP-PCNAL2 fusion protein (Leonhardt et al., 2000) was provided by Cristina Cardoso (Technishe Universität Darmstadt, Germany) and inserted in a pFlox-pA-EGFP plasmid (Morin et al., 2007) for the clonal expression of the fusion protein PCNA-GFP. The pCX-Cre (Morin et al., 2007) and pFlox-pA-PCNA-EGFP plasmids were coelectroporated at $0.0002 \mu \mathrm{g} / \mu \mathrm{L}$ and $0.5 \mu \mathrm{g} / \mu \mathrm{L}$ concentration, respectively.

\subsection{In utero electroporation}

Electroporations were performed on E14 or E15 mouse embryos according to published procedures (Osumi \& Inoue, 2001; Tabata \& Nakajima, 2001). Pregnant mice were anesthetized using a mix of 2\% Rompun and Ketamin (Imalgen 1,000). Plasmids solutions were prepared using sterile PBS, Fast Green $0.1 \%$. $1.5 \mu \mathrm{L}$ of plasmids solution was micro-injected through the uterine wall in the ventricle of one embryonic hemisphere using a $1 \mathrm{~mm}$ diameter glass capillary (Harvard Apparatus, Edenbridge, UK). Three embryos per horn were injected. Using a pair of electrodes (Tweezertrodes, Harvard Apparatus, Edenbridge, UK), of 5 or $10 \mathrm{~mm}$ of diameter (for E14 and E15 embryos, respectively), the ventricular zone of the medial cortex was targeted. Five pulses of electric current ( $40 \mathrm{~V}$ or $60 \mathrm{~V}$ for E14 or E15 embryos, respectively, $50 \mathrm{~ms}$ on/1000 ms off) were delivered by the BTX Electro Square Porator ECM 830.

\subsection{Confocal microscopy analysis}

Confocal acquisitions were performed on a Leica DM 6000 CS using the oil objective $x 40$, a x2.5 zoom and thanks to the Leica software LAS AF. Four lasers are used to excite the fluorochromes: an argon laser settled at $488 \mathrm{~nm}$, a HeNe laser at $543 \mathrm{~nm}$, a HeNe laser at $633 \mathrm{~nm}$ and a diode settled at $405 \mathrm{~nm}$.

\subsection{Cell-cycle distribution analysis}

The CellCounter plugin (https://imagej.nih.gov/ij/plugins/cell-counter) of the ImageJ software (https://imagej.nih.gov/ij/, RRID:SCR_003070) was used to plot the different cell population.

Organotypic slices culture: Embryonic brains were dissected in cold PBS using a binocular loupe and placed in cold Hank's buffered salt solution (HBSS) (Gibco, Thermo Fisher Scientific, Rockford, IL, USA) supplemented with glucose $18 \%, \mathrm{MgSO} 4$ and $\mathrm{CaCl} 2$ before they were embedded in $37^{\circ} \mathrm{C}$ supplemented HBSS containing 3\% of agarose (Sigma-Aldrich, Saint-Quentin Fallavier, France). Slices of $200 \mu \mathrm{m}$ were realized in the coronal plane thanks to a vibratome (Leica VT1000S) and placed into laminin-poly-lysine (Sigma-Aldrich, SaintQuentin Fallavier, France) coated $0.4 \mu \mathrm{m}$ millicell culture insert (Millipore, Merck Millipore, Molsheim, France) on a drop of type 1 collagen (BD Biosciences, Le Pont de Claix, France). Slices were cultured at $37^{\circ} \mathrm{C}$ and $7.5 \% \mathrm{CO} 2$, in a 6-well plate (Falcon) and within $1 \mathrm{~mL}$ of Glasgow minimum essential medium (GMEM, Gibco, Thermo Fisher Scientific, Rockford, IL, USA) supplemented with $1 \%$ sodium pyruvate, $7.2 \mu \mathrm{M}$ beta-mercaptoethanol, $1 \%$ nonessential amino acids, $2 \mathrm{mM}$ glutamine, 1\% penicillin/streptomycin and $10 \%$ fetal calf serum (FCS). Acquisitions were taken for $48 \mathrm{hr}$ and culture medium was change in the morning and in the evening. After videorecording, slices were fixed during $1 \mathrm{hr}$ using $2 \% \mathrm{PFA}$ and kept at $4{ }^{\circ} \mathrm{C}$ in $\mathrm{PB}$ supplemented with azid.

\subsection{Time-lapse videorecording}

Videorecording was performed using a two-photon microscope (inverted Axio-Observer Z1, Zeiss). Slices were kept in microscope cage incubation under the following parameters: $7.5 \% \mathrm{CO} 2$ and $37^{\circ} \mathrm{C}$. Laser was tuned to $880 \mathrm{~nm}$ in order to visualize the GFP. Observations were performed using a plan apochromatic dry objective $10 \mathrm{x} / 0.45$. Acquisitions were taken using the multi-time series macro of the Zeiss software, 4D stacks (x, y, z, time) were acquired on a $114 \mu \mathrm{m}$ thickness (divided in 20 sections). Acquisitions were started $24 \mathrm{hr}$ after electroporation, images were acquired every $30 \mathrm{~min}$ during $48 \mathrm{hr}$. Films were concatenated with a macro of the Image $\mathbf{J}$ software. 


\subsection{APs tracking and velocity measurements}

The MTrackJ plugin (https://imagescience.org/meijering/software/ mtrackj/) of the ImageJ software (https://imagej.nih.gov/ij/, RRID: SCR_003070) was used to track the APs nuclei. Velocity was automatically measured by the plugin.

\subsection{Statistical significance}

The R software (http://www.r-project.org/, RRID:SCR_001905) was used to perform statistical analysis - boxplots and tests. The level of significance was determined using a chi-square independencetest to compare two qualitative data sets, Mann-Whitney test when two samples of unpaired data were analyzed, a Kruskal-Wallis test when more than two samples of unpaired data were analyzed and a Friedman test followed by Wilcoxon along with a Bonferroni correction post hoc test when more than two samples of paired data were analyzed.

\section{RESULTS}

In previous INM descriptions, S phase cells have been identified via incorporation of a thymidine analog (BrdU, EdU, H3-Thy) and M phase according to morphological criteria (mitotic figures) (Murciano, Zamora, Lopez-Sanchez, \& Frade, 2002; Sauer \& Walker, 1959; Tamai et al., 2007). The nuclei of S phase progenitors have been reported to reside in the most basal part of the VZ while M phase APs at its most apical end. Time-lapse microscopy, combined with BrdU labeling suggested that apical nuclear migration begins shortly after entering G2 phase (Kosodo et al., 2011; Miyata, Kawaguchi, Okano, \& Ogawa, 2001; Noctor et al., 2001; Sugiyama et al., 2009; Tamai et al., 2007) (Figure 1a). However, the absence of selective G1 and G2 phases markers for in situ observations, led to an imprecision in the allocation of these phases in the INM. This has prompted us to establish an unambiguous methodology for a positive identification of all four cell-cycle phases of APs.

\subsection{Validation of PCNA/Ki-67 immunolabeling-based identification of cell-cycle phases}

The Ki-67 and PCNA antigens are classically used to detect cycling cells. Ki-67 is a 360 KDa protein known as a heterochromatin organizer. It forms discrete foci throughout the nucleoplasm during the G1 phase, whereas it is localized within the nucleolus during S and G2 phases (Kill, 1996; Winking, Gerdes, $\&$ Traut, 2004). It is associated with chromosomes during mitosis (Starborg et al., 1996). As a result, Ki-67 has been shown to exhibit a phase-specific pattern of expression: during G1 phase, the Ki-67 labeling is punctuated whereas it appears diffuse during S and G2 phases, due to an expansion of the foci covering the nucleoli (Kill, 1996; Starborg et al., 1996). PCNA, a 36 KDa protein and a central component of the replication machinery, is another marker of cycling cells. PCNA label shows a diffuse nuclear distribution during G1 and G2 phases and a diffuse cellular distribution in M phase following nuclear envelope breakdown (Leonhardt et al., 2000; Leung, Klopper, Grill, Harris, \& Norden, 2011). It is relocated to the replication forks at the G1/S transition: early $S$ phase cells exhibit a punctuate pattern with small dots covering the nucleus, whereas late $\mathrm{S}$ phase cells are characterized by larger dots. By combining Ki-67 and PCNA immunolabeling, we identified four distinct populations of APs: (a) cells with nuclei exhibiting small punctuate PCNA labeling (early S phase cells) (b) cells with nuclei exhibiting large punctuate PCNA labeling (late S phase cells); (c) cells exhibiting Ki-67 dots throughout the nucleus (G1 phase cells) and (d) cells showing a diffuse Ki-67 staining (G2 phase) as shown in Figure 1b,c.

We validated the correspondence between G1, S, G2, and M phases and the PCNA/Ki-67 immunolabeling patterns, by comparing the proportions of cells in each phase of the cell-cycle returned by flow cytometry analysis with the proportions computed after immunolabeling in 3T6 fibroblasts. In the $3 \mathrm{~T} 6$ cell line, $100 \%$ of cells are cycling due to absence of contact inhibition so that it does not include a G0 fraction (Wittelsberger, Kleene, \& Penman, 1981). This was an important requirement in the choice of the cell line, given that flow cytometry analysis fails to distinguish between G0 and G1 phase cells. 
Flow cytometry analysis returned $29.9 \%$ of G1 cells, $52.4 \%$ of S, and $15.7 \%$ in G2/M (Figure $1 \mathrm{~d}$ and FACS in Figure 1e). By comparison, the immunolabeling revealed $27.7 \%$ of G1 cells, $61.6 \%$ of S, $10.7 \%$ in G2 (Plot in Figure 1e). These two distributions are not statistically different as shown by the chisquare test, meaning that the immunolabeling techniques based on the pattern of PCNA/Ki-67 expression is a valid tool to compute the proportions of progenitors in $\mathrm{G} 1, \mathrm{~S}$, and $\mathrm{G} 2 / \mathrm{M}$ phases.

a



b

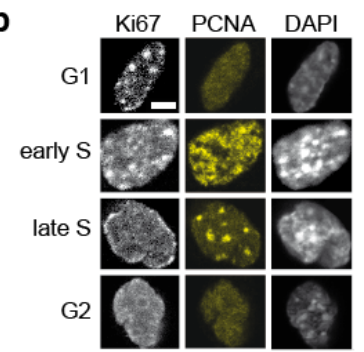

d

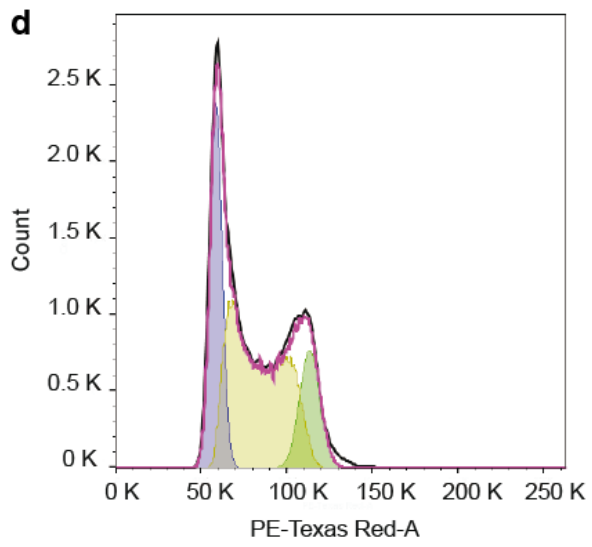

C

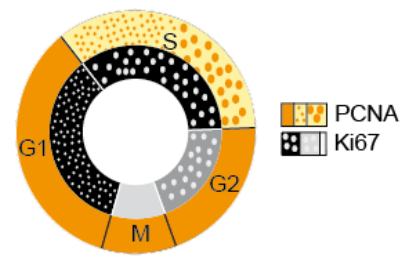

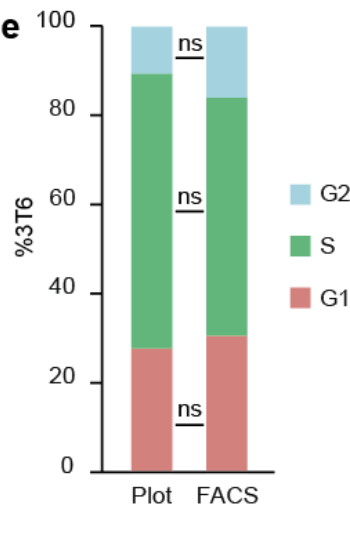

FIGURE 1. PCNA and Ki-67 immunolabeling allows to accurately determine the proportion of cells in each phase of the cell-cycle. (a) Cartoon representing the accepted relationship between INM and cell-cycle phases in the VZ. (b) Microphotographs of Ki-67 and PCNA immunolabeling in $3 \mathrm{~T} 6$ fibroblasts, counterstained with DAPI. Four distinct populations of cells based on their labeling: (i) cells whose nuclei exhibit small punctuate PCNA labeling (early S phase cells) (ii) nuclei with large punctuate PCNA labeling (late S phase cells); (iii) cells with Ki-67 dots throughout the nucleus (G1 phase) and (iv) cells showing a more diffuse Ki67 staining (G2 phase). Scale bar $=2 \mu \mathrm{m}$. (c) Cartoon illustrating the punctuated or diffuse pattern of Ki-67 (in black/gray) and PCNA (in light and dark yellow) with respect to the different phases of the cell-cycle. (d) Flow cytometry profile of 3T6 fibroblasts using PI-staining for cell-cycle analysis. Analysis with Flowjo software revealed that $29.9 \%$ of cells were in G1, $52.4 \%$ in S-phase and $15.7 \%$ in G2/M-phase using the Watson (pragmatic) model. (e) Histograms showing the distribution of 3T6 cells in the cell-cycle as revealed by computation of PCNA/Ki-67 immunolabeled cells (plot) and by flow cytometry (FACS). The distributions do not statistically differ as assessed by a chi-square test.

\subsection{In situ analysis of cell-cycle distribution of APs in the VZ at E12, E14, and E16}

In a first step, we quantified the percentage of cycling APs by computing the proportion of Ki-67+ cells with respect to the total VZ population (DAPI+). We observed a decrease from 100 to $97 \%$ of Ki-67+ APs, indicating a moderate reduction in the growth fraction (Caviness et al., 1995; Miyama, Takahashi, Nowakowski, \& Caviness, 1997; Takei \& Endo, 1994). Using the Ki-67/PCNA immunolabeling procedure, we then computed the proportions of APs in the different cell-cycle phases (Figure 2a,b). The results show between E12 to E16 a significant increase in the relative proportion of G1 phase APs, accompanied by a significant decrease of S phase Aps (Figure 2c). When calculated within the cycling population (Ki-67+), the proportions of APs in the four cell-cycle phases defines the relative duration of each cell-cycle phase. Therefore, comparison of these proportions at different stages informs on relative differences in cell-cycle progression. Our results indicate a progressive lengthening of G1 phase from E12 to E14 as well as a shortening of S phase, in agreement with published data based on in vivo analysis of cell-cycle kinetics (Arai et al., 2011; Calegari et al., 2005; Lukaszewicz, Savatier, Cortay, Kennedy, \& Dehay, 2002). This congruence between the present in situ observations and in vivo data further validates the reliability of the PCNA/Ki-67 immunolabeling technique to identify cell-cycle phases in APs. 

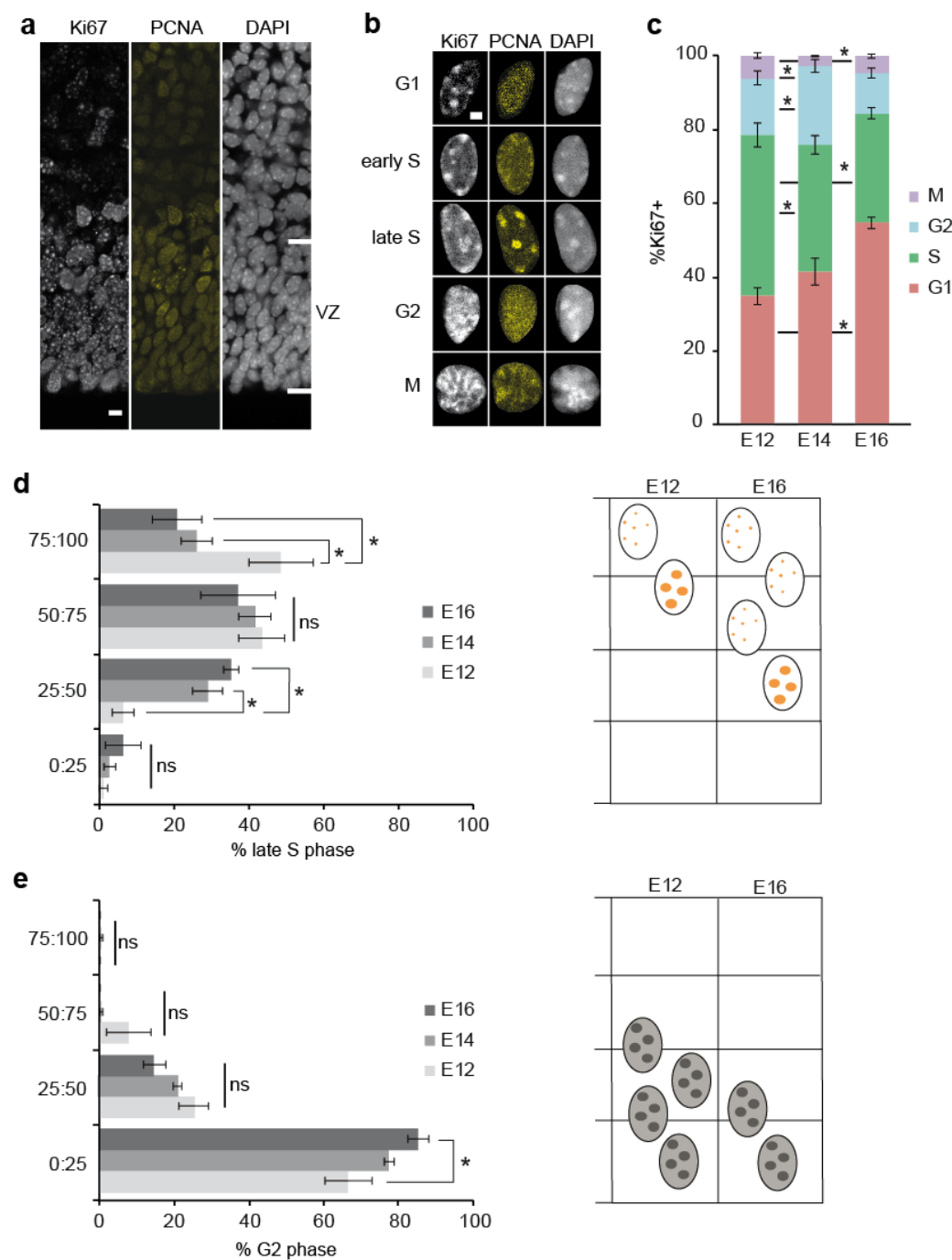

FIGURE 2. Cell-cycle distribution of cycling APs in the VZ as revealed by immunolabeling. (a) Microphotograph of the E16 VZ showing Ki-67, PCNA labeling and DAPI staining. (b) Microphotographs of Ki-67 and PCNA immunolabeling in VZ progenitors, counterstained with DAPI. Five distinct populations of cells based on their labeling: (i) cells whose nuclei exhibit small punctuate PCNA labeling (early S phase cells) (ii) nuclei with large punctuate PCNA labeling (late S phase cells); (iii) cells with Ki-67 dots throughout the nucleus (G1 phase), (iv) cells showing a more diffuse $\mathrm{Ki}-67$ staining (G2 phase) and (v) mitotic cells. Scale bar $=2 \mu \mathrm{m}$. (c) Histograms showing the proportions of APs in G1, S, G2, and $M$ phases at E12, E14, and E16. Scale bar $=5 \mu \mathrm{m}$. (d) Distribution of late $\mathrm{S}$ phase APs in the depth of the VZ at E12, E14, and E16. Late S phase cells are observed more apically as development proceeds as depicted on the cartoon representing early (small punctuate) and late (large punctuate) $\mathrm{S}$ phase nuclei. (e) Distribution of G2 phase APs in the depth of the VZ at E12, E14, and E16. G2 phase cells are observed more basally as development proceeds as depicted on the cartoon. Significance of the results was assessed using a Kruskal-Wallis test with E12 as control, error bars represent the SEM. p values: $<0.05^{*}$, $<0.01 * *,<0.005 * * *$

In a second step, we examined the distribution of G1, S, G2, and M phase APs nuclei at different apico-basal depths of the VZ. The VZ was divided in four horizontal bins of equal width, spanning from the apical surface at the ventricular border to the basal surface, at the boundary with the SVZ (Figure $2 \mathrm{~d}, \mathrm{e})$. At all stages, $M$ phase APs were observed at the apical border and G1 phase nuclei were scattered through the VZ depth (Figure 2a). At E12, S phase APs nuclei were found to be restricted to the upper basal half, in agreement with published data. By contrast, we observed an unexpected scattering of $\mathrm{S}$ phase nuclei at E16. Indeed, a detailed analysis based on the PCNA punctuate expression pattern showed that at E16, 42\% of late S phase APs nuclei were observed in the lower half of the VZ, including $6.5 \%$ in the lowest bin, in the vicinity of the ventricular border (Figure 2d). Compared to E12, the G2 phase APs nuclei in the E16 VZ are underrepresented in the second basal bin and 85.4\% of G2 nuclei are located in the most apical bin (Figure 2e). This apical shift in the distribution of S phase APs nuclei at E16 raises questions related to the apical movement, considered to be initiated at the beginning of the G2 phase (Guerrier \& Polleux, 2007; Latasa, Cisneros, \& Frade, 2009; Pearson, Luneborg, Becker, \& Mobbs, 2005; Sauer \& Walker, 1959).

\subsection{Single-cell real time imaging reveals distinct kinetic phases during the apical movement at midcorticogenesis}

The above in situ observations on fixed tissue suggest that at E16, APs nuclei initiate their apical migration while they are still in S phase and that G2 is occurring when the nuclei are near the ventricular 
border. This prompted us to examine the dynamics of apical directed nuclear migration with respect to $\mathrm{S}$ phase at the single cell level, using real time imaging. We expressed a GFP tagged version of PCNA via in utero targeted clonal electroporation (Leonhardt et al., 2000). This makes it possible to monitor the PCNA expression pattern in APs undergoing INM under timelapse videomicroscopy as shown in the zebrafish retina (Leung et al., 2011). Using two photons live imaging, we observed large punctuaindicative of late S phase - in the APs nuclei after initiation of the apical directed migration (Figure 3a). These large punctua become diffuse, indicating the S-G2 transition when nuclei further have completed about 50\% (G2 mean distance $=30 \mu \mathrm{m}$ and apical movement mean distance $=68 \mu \mathrm{m}$, data not shown) of their apical descent (see frame 4:30 Figure 3a). This indicates that the apical movement does not entirely correspond to G2 phase and that G2 phase occurs when the apical migration is already well engaged. The analysis of the kinetics of the apical nuclear migration reveals two segments (Figure 3b,c), each characterized by distinct velocities (Figure 3c). The first segment corresponding to the beginning of the descent from the basal border by S phase APs nuclei (Part1 in Figure 3), exhibits a low velocity compared to the descent motion by G2 nuclei (G2 in Figure 3). This cell-cycle phase difference in velocity points to cell-cycle related differences in the apical movement. In addition, we noticed that the apical movement velocity appeared faster in some nuclei at the beginning of the descent. This prompted us to extract the velocity of the first 30 min of the apical movement (see "initiation" in Figure $3 \mathrm{~d}$ ). Although not statistically significant, a fraction of nuclei show a higher velocity while initiating the apical movement than when engaged in the descent (up to $58 \mu \mathrm{m} / \mathrm{hr}$ ).
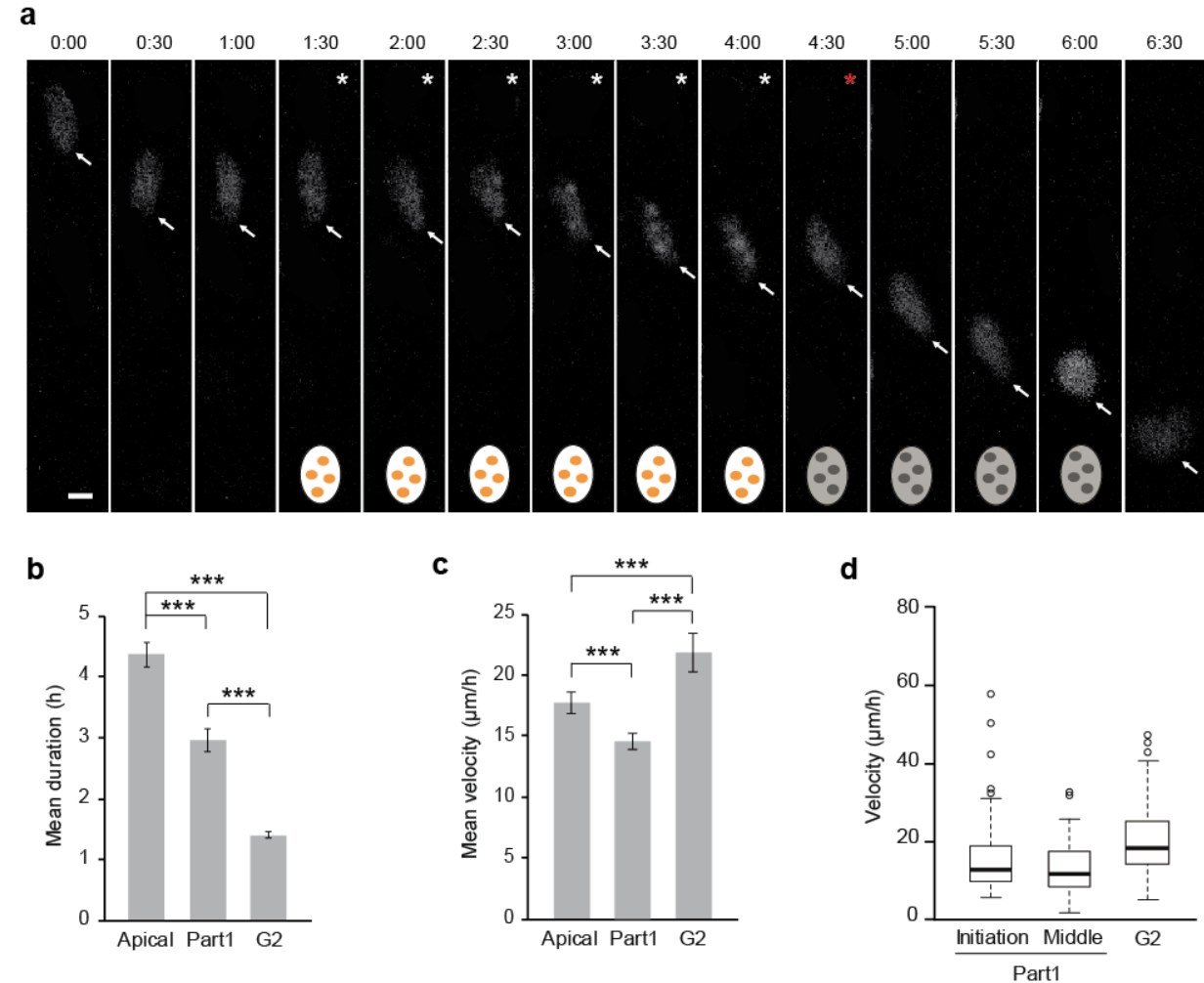

FIGURE 3. Time-lapse videomicroscopy analysis of PCNA-GFP expressing APs during the apical movement of INM. (a) Microphotographs extracted from a movie, showing the apical migration of an AP at E15 following PCNA-GFP overexpression at E14. The nucleus exhibits large PCNA dots (detectable on photographs indicated by a white star) indicative of late S phase and the dissolution of PCNA labeling corresponding to G2 phase transition (red star). Scale bar $=5 \mu \mathrm{m}$. (b) Histograms showing the duration of the apical movement and of its two segments: part1 when the cell is in S phase and G2. (c) Histograms showing the velocity of the two segments of the apical movement d: Boxplots showing the velocity of the initiation of the apical movement, the middle part (initiation and middle part correspond to part 1) and the G2 segment. Significance of the results was assessed using a Friedman test followed by a post hoc analysis with a Wilcoxon test along with a Bonferroni correction, error bars represent the SEM. p values: $<0.05^{*},<0.01 * *,<0.005^{* * *}$ 


\subsection{Experimental cell-cycle kinetics modification at midcorticogenesis alters INM dynamics}

Cyclin E overexpression in APs at midcorticogenesis has been shown to accelerate cell-cycle progression in the VZ, by shortening G1 phase duration (Pilaz et al., 2009). We then asked the question whether and how enforcing shorter cell-cycle duration - a characteristic of early corticogenesis - in the E16 VZ might affect INM dynamics. In utero co-electroporation of a GFP and a Cyclin E plasmid targeted APs at E14 or E15 was performed, followed by real time imaging on organotypic slices (E14$>$ E15) and in situ analysis (E15- $>$ E16) on fixed tissue. Time lapse video experiments evidenced a global mean cell-cycle reduction of Cyclin E electroporated APs with respect to control APs (17 hr 32 min vs $19 \mathrm{hr} 36 \mathrm{~min}$ ) (Figure 4a), in agreement with previous data (Pilaz et al., 2009). Accordingly, the in situ immunolabeling analysis revealed a drastic reduction of the relative proportion of G1 phase in the Cyclin E GOF APs within the GFP + APs population. This was accompanied by a significant increase in the proportions of both S and G2 phases (Figure 4b). The increase in S phase frequency was largely due to an important expansion of the late $\mathrm{S}$ phase frequency.

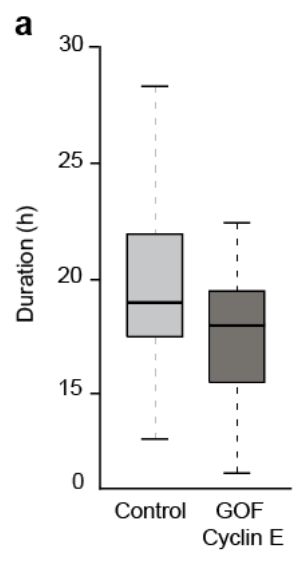

c

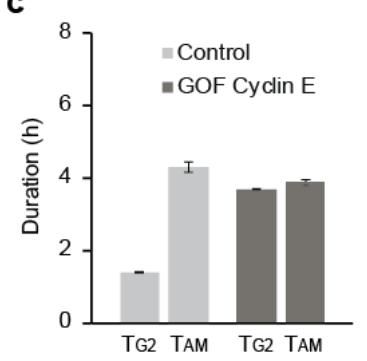

b

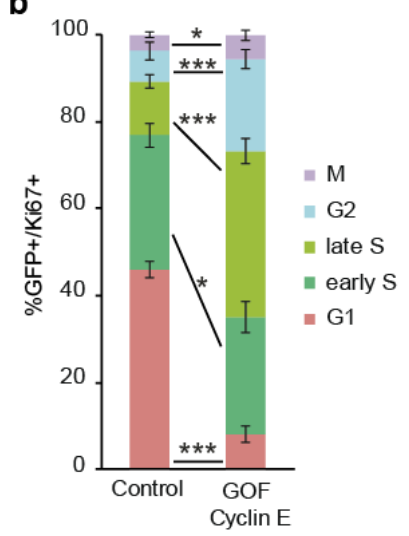

d

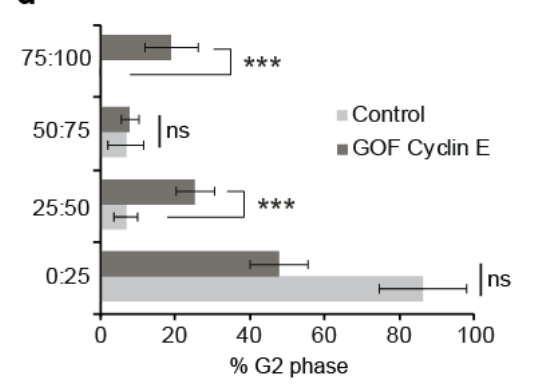

FIGURE 4. Experimental cell-cycle kinetics modification at midcorticogenesis alters INM dynamics. (a) Boxplot representing the cell cycle duration of control and Cyclin E GOF APs at E15E16 as shown by TLV. (b) Histograms showing the proportions of G1, early S, late S, G2, and M phases in control and Cyclin E GOF GFP+ APs at E16 after Cyclin E overexpression at E15. (c) Histograms showing G2 extrapolated durations, calculated using the mean cell-cycle duration obtained from TLV combined with the proportion of G2 phase obtained with the immunostaining approach, compared to the duration of the apical movement (AM) obtained from TLV in both control and GOF Cyclin E conditions. (d) Distribution of GFP+ APs in G2 phase in the depth of the VZ at E16 after Cyclin E overexpression at E15. (E) Cartoon comparing the INM profile of a control and a Cyclin E GOF at E16. Significance of the results was assessed using a Wilcoxon test, error bars represent the SEM. p values: $<0.05^{*},<0.01^{* *},<0.005^{* * *}$
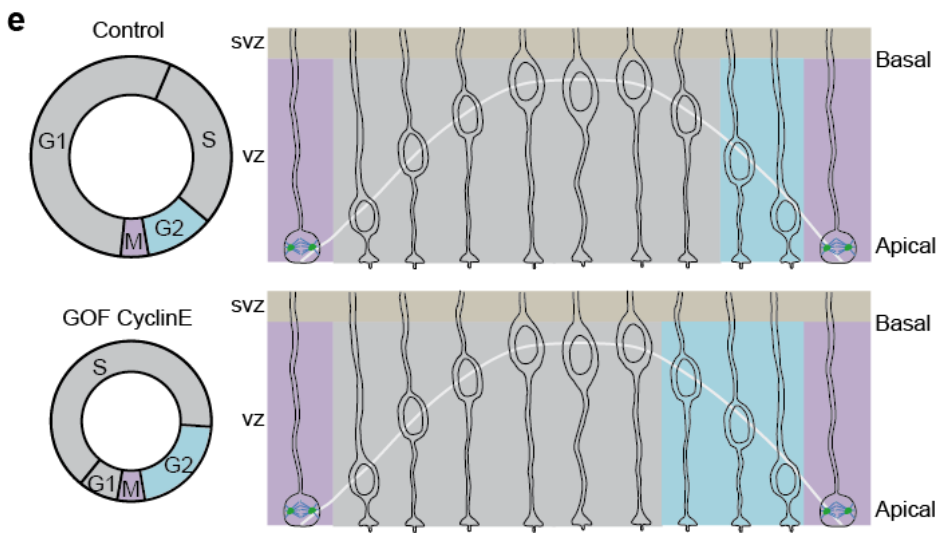
The TLV observations reveal that the duration of the apical movement does not significantly vary between control (4 hr $18 \mathrm{~min}$ ) and Cyclin E GOF APs (3 hr $54 \mathrm{~min}$ ). The computed duration of the G2 phase in control APs is $1 \mathrm{hr} 24 \mathrm{~min}$ ( $7 \%$ of $19 \mathrm{hr} 36 \mathrm{~min}$ ), which is significantly shorter than the $4 \mathrm{hr} 18$ min duration of the apical movement (Figure 4c), in agreement with the above data (G2 duration $1 \mathrm{hr}$ 22 min using TLV of PCNA-GFP expressing APs). By contrast, G2 phase is estimated to last $3 \mathrm{hr} 40$ min in Cyclin E GOF (21\% of $17 \mathrm{hr} 32 \mathrm{~min}$ ), which is not statistically different from the $3 \mathrm{hr} 54 \mathrm{~min}$ duration of the apical movement in Cyclin E GOF APs (Figure 4c). This indicates that in Cyclin E GOF, the G2 phase and the apical movement are congruent, as is observed at E12 (Figure 2).

These differences in the correspondence between G2 phase and the apical movement in control and Cyclin E GOF APs were confirmed by the analysis of the depth distribution of the G2 phase nuclei in the VZ. A significantly higher proportion of $\mathrm{G} 2$ nuclei were observed in the most basal bin and in middle lower bin after Cyclin E GOF (Figure 4d,e).

Together, our data show that the INM dynamics change during early and midcorticogenesis and that forced cell-cycle shortening can revert these changes during the apical movement. These findings are illustrated in an explanatory cartoon (Figure 5).

\section{DISCUSSION}

\subsection{In situ analysis of cell-cycle kinetics in the $\mathrm{VZ}$}

INM like the cell-cycle is a dynamic process and ideally, investigation of the correlation between cellcycle progression and INM dynamics requires real time imaging of progenitors expressing distinct fluorescent markers in the different phases of the cell-cycle. The recently improved Fucci system distinguishes G1, S, and G2 phases thanks to CUL4Ddb1 and APCCdh1 E3 ligase activities (SakaueSawano et al., 2017). However, this system suffers limitations making it difficult to reliably distinguish the different cell-cycle phases. Further, while working well on dissociated cells, the Fucci system is challenging to implement in organotypic slices.

We have established an alternative immunolabeling method to derive cell-cycle distribution at the population level, based on the combined expression of Ki-67 and PCNA. The proportions of APs in the different cell-cycle phases, as determined by PCNA/Ki-67 labeling matched those returned by flow cytometry analysis (Figure 1). This technique therefore constitutes a reliable tool to identify cell-cycle phases in situ. This is further confirmed by our in situ analysis of cell-cycle distribution on fixed tissue which returned values in agreement with in vivo cell-cycle kinetics analysis (Arai et al., 2011; Caviness et al., 1995).

\subsection{The apical nuclear movement is not restricted to G2 phase at midcorticogenesis}

INM in the mouse and rat VZ has been described by several groups using time-lapse video analysis (Miyata et al., 2001; Noctor et al., 2001). Real time imaging combined with BrdU labeling suggested that the apical nuclear movement is initiated soon after the APs enter G2 phase (Tamai et al., 2007). A series of published data support the notion that the completion of S phase is necessary for APs nuclei to engage in apical movement. Overexpression of $\mathrm{p} 18^{\mathrm{Ink4c}}$, which arrests cells in G1 phase, results in an accumulation of APs in the basal region of the VZ (Kosodo et al., 2011). Cyclophosphamide-induced arrest in S-phase prevents apical directed nuclear movement (Ueno, Katayama, Yamauchi, Nakayama, \& Doi, 2006). Morphine, which slows down APs cell-cycle progression by increasing G2/M duration delays the onset of INM apical movement (Sargeant et al., 2008). In the retina, Leung et al. (2011)) reported that arresting the progenitors cell-cycle progression with aphidicolin and hydroxyurea inhibits the apical directed movement. By contrast, inhibition of S phase with hydroxyurea does not inhibit the nuclear apical movement in the stage 18 chicken diencephalon (Murciano et al., 2002).

Using time-lapse videomicroscopy of PCNA-GFP expressing APs, we showed that at stage E16, the nuclei of APs engage apical directed movement during S phase. At E16, the dynamics of the apical 
movement can be subdivided in two segments: (a) beginning of the descent from the basal border while APs are still in S phase and (b) descent motion while APs are in G2 phase. The nuclei in G2 phase directed motion occurs at a much faster pace than nuclei in S phase, pointing to cell-cycle control of INM dynamics. Interestingly, Kosodo et al. (2011) proposed that the cell-cycle-regulated release of TPX2, a microtubule-binding protein that reorganizes the microtubule cytoskeleton, is essential for apical directed movement. TPX2 is contained in the nucleus prior to G2 phase, and translocates to the apical during the S-G2 transition.

TLV recordings in Zebrafish retina (Strzyz et al., 2015) and in the rat developing cortex (Baffet et al., 2015) showed that CDK1 - which expression initiates G2 phase (Hochegger, Takeda, \& Hunt, 2008 - is involved in triggering the apical movement. In the Zebrafish retina, inhibition of CDK1 impedes the apical movement, just after the completion of S phase, as revealed by the PCNA reporter assay (Strzyz et al., 2015). Inhibition of CDK1 with RO3306 in the rat VZ blocks the apical movement and APs are stalled at the basal border of the VZ (see movie S2, S4, and S5 in Baffet et al., 2015). In agreement, expression of a dominant-negative of CDK1 leads to a stalling of nuclei $>30 \mu \mathrm{m}$ away from the ventricle (Baffet et al., 2015) and they never undergo the apical descent. However, due to the impossibility of monitoring cell-cycle progression, it cannot be ruled out that the rat APs are blocked before G2, in S phase. Premature activation of CDK1 (using PD166285) - revealed S nuclei (BrdU+) at the ventricular border suggesting that CDK1 triggers the apical movement, independently of the cellcycle phase (Baffet et al., 2015). Together these observations suggest that CDK1 might regulate cellcycle progression in G2 and trigger the apical movement via two different mechanisms in the rodent developing cortex.

The Vallee lab also showed that CDK1 regulates dynein recruitment (Baffet et al., 2015). As dynein does not appear to be involved in the apical movement in the Zebrafish retina (Norden et al., 2009), one can hypothesize that the CDK1 role in coupling G2 phase entry with apical movement initiation may have undergone evolutionary adaptation, via regulating dynein interaction in the rodent VZ.

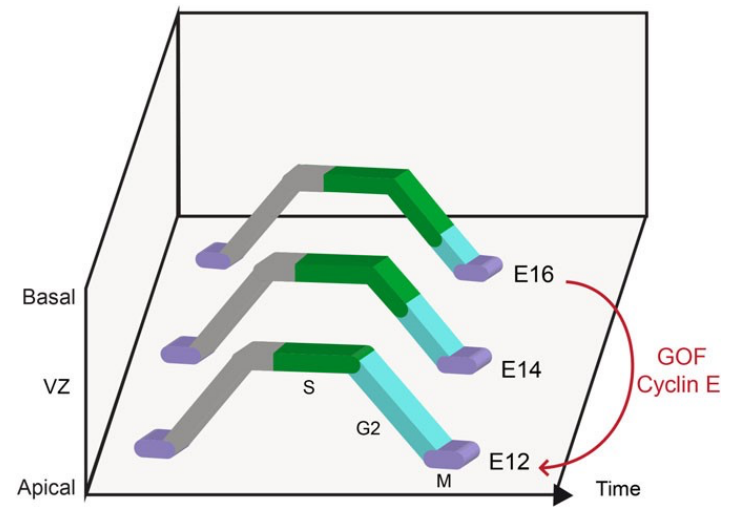

FIGURE 5. Cartoon illustrating the developmental changes in the relationship between INM dynamics and cell-cycle progression as well as the impact of CyclinE overexpression. As development proceeds, the relative duration of G1 phase decreases while the relative duration of $\mathrm{S}$ phase increases. At midcorticogenesis, nuclei initiate G2 phase when they are well engaged in the apical movement. At E16, Cyclin E overexpressing APs show an INM behavior reminiscent of that observed in E12 Aps.

\subsection{Developmental variations in the relationship between cell-cycle progression and INM: Crossspecies comparison and evolutionary perspective}

Our results reveal that INM dynamics change over the course of mouse corticogenesis (Figure 5). During early corticogenesis, the relationship between cell-cycle progression and INM in the VZ is reminiscent of the situation described in the Zebrafish retina (Lahne, Li, Marton, \& Hyde, 2015; Leung et al., 2011; Spear \& Erickson, 2012; Strzyz et al., 2015) where the VZ is thin (circa $50 \mu \mathrm{m}$ ) and cell-cycle duration is short (10 hr maximum) (Leung et al., 2011). By comparison, APs cell-cycle duration in the mouse ranges from $8 \mathrm{hr}$ at early stages to $18 \mathrm{hr}$ at late stages in mouse (15 hr at E16). This increase in cellcycle duration is not accompanied by overall changes in VZ thickness: $80 \mu \mathrm{m}$ at E12 and $77 \mu \mathrm{m}$ at E16 (Caviness et al., 1995; present data). It can therefore be hypothesized that the INM of progenitors with 
a short cell-cycle duration differs from that of progenitors with longer cell-cycle duration, independently of the species or the tissue considered. This is further supported by our results showing that forced shortening of the cell-cycle at E16 leads APs to adopt INM features reminiscent of earlier stages.

Cytological differences between mice and ferrets VZ related to thickness and cell density (higher in ferrets) are accompanied by different INM dynamics. Compared to the mouse, ferrets APs show a slower apical movement during G2 and a faster basal movement during G1 (Okamoto et al., 2014). Together, these observations suggested that APs INM behavior can adapt in response to physical parameters of the VZ microenvironment (Okamoto et al., 2014). The present data based on Cyclin E overexpression provides new insight to this issue by showing that short-term cell-cycle modifications per se can also alter INM, independently of thickness and crowding.

The present results as well as observations in the ferret may bear relevance for evolutionary adaptations. For instance, during primate cortical development, there is a reduction in VZ thickness at early stages of corticogenesis (Smart, Dehay, Giroud, Berland, \& Kennedy, 2002) and cell-cycle variations of APs follow a different schedule than that of the mouse, with a transient shortening of the cell cycle at midcorticogenesis (Betizeau et al., 2013; Kornack \& Rakic, 1998).

\section{ACKNOWLEDGMENTS}

we thank Véronique Cortay, Angèle Bellemin Ménard and Claire Millet for excellent technical assistance; Brigitte Beneyton, Xavier Biolchini and Muriel Séon for animal care. We thank Xavier Morin for the pCX-Cre and pFlox-pA-EGFP constructs, James Briscoe and Laurent Nguyen for pCAGGS-IRES-GFP construct and Cristina Cardoso for the GFPPCNAL2 construct. We are indebted to Nathalie Doerflinger for plasmid construction and to Nolwenn Pasquet for help with mouse experiments. We thank Pierre-Yves Bourillot for help with flow cytometry experiments, Maxime Petit and Bertrand Beffara for help with R software. We thank Caren Norden, Alexandre Baffet, David Price and Pierre Savatier for suggestions and discussions at the early stages of the study. We are indebted to Henry Kennedy for helpful discussions and critical reading of the manuscript. Financial support from FP7 SECO grant (FP7-2007 ICT216593), LABEX CORTEX (ANR-11-LABX-0042), LABEX DEVWECAN (ANR-10-LABX-0061) of Université de Lyon (ANR-11-IDEX-0007) operated by the French National Research Agency (ANR), ANR14-CE13-0036 (Primacor), FRM grant no FDT20150532412 and FRM Equipe DEQ20160334943 is acknowledged.

\section{REFERENCES}

Acs, B., Kulka, J., Kovacs, K. A., Teleki, I., Tokes, A. M., Meczker, A., ... Szasz, A. M. (2017). Comparison of $5 \mathrm{Ki}-67$ antibodies regarding reproducibility and capacity to predict prognosis in breast cancer: Does the antibody matter? Human Pathology, 65, 31-40.

Arai, Y., Pulvers, J. N., Haffner, C., Schilling, B., Nusslein, I., Calegari, F., \& Huttner, W. B. (2011). Neural stem and progenitor cells shorten Sphase on commitment to neuron production. Nature Communications, 2, 154.

Attardo, A., Calegari, F., Haubensak, W., Wilsch-Brauninger, M., \& Huttner, W. B. (2008). Live imaging at the onset of cortical neurogenesis reveals differential appearance of the neuronal phenotype in apical versus basal progenitor progeny. PLoS One, 3(6), e2388.

Baffet, A. D., Hu, D. J., \& Vallee, R. B. (2015). Cdk1 activates pre-mitotic nuclear envelope dynein recruitment and apical nuclear migration in neural stem cells. Developmental Cell, 33(6), 703-716.

Betizeau, M., Cortay, V., Patti, D., Pfister, S., Gautier, E., BelleminMenard, A., ... Dehay, C. (2013). Precursor diversity and complexity of lineage relationships in the outer subventricular zone (OSVZ) of the primate. Neuron, $80,442-457$. 
Bort, R., Signore, M., Tremblay, K., Martinez Barbera, J. P., \& Zaret, K. S. (2006). Hex homeobox gene controls the transition of the endoderm to a pseudostratified, cell emergent epithelium for liver bud development. Developmental Biology, 290(1), 44-56.

Calegari, F., Haubensak, W., Haffner, C., \& Huttner, W. B. (2005). Selective lengthening of the cell cycle in the neurogenic subpopulation of neural progenitor cells during mouse brain development. The Journal of Neuroscience, 25(28), 6533-6538.

Carabalona, A., Hu, D. J., \& Vallee, R. B. (2016). KIF1A inhibition immortalizes brain stem cells but blocks BDNF-mediated neuronal migration. Nature Neuroscience, 19(2), 253-262.

Carroll, T. D., Langlands, A. J., Osborne, J. M., Newton, I. P., Appleton, P. L., \& Nathke, I. (2017). Interkinetic nuclear migration and basal tethering facilitates post-mitotic daughter separation in intestinal organoids. Journal of Cell Science, 130(22), 3862-3877.

Caviness, V. S., Takahashi, T., \& Nowakowski, R. S. (1995). Numbers, time and neocortical neuronogenesis: A general developmental and evolutionary model. Trends in Neurosciences, 18(9), 379-383.

Dowsett, M., Nielsen TO, A'Hern, R., Bartlett, J., Coombes, R. C., Cuzick, J., ... International Ki-67 in Breast Cancer Working G. (2011). Assessment of Ki67 in breast cancer: Recommendations from the international Ki67 in breast cancer working group. Journal of the National Cancer Institute, 103(22), $1656-1664$.

Götz, M., \& Barde, Y. A. (2005). Radial glial cells defined and major intermediates between embryonic stem cells and CNS neurons. Neuron, 46 (3), 369-372.

Grosse, A. S., Pressprich, M. F., Curley, L. B., Hamilton, K. L., Margolis, B., Hildebrand, J. D., \& Gumucio, D. L. (2011). Cell dynamics in fetal intestinal epithelium: Implications for intestinal growth and morphogenesis. Development, 138(20), 4423-4432.

Guerrier, S., \& Polleux, F. (2007). The ups and downs of neural progenitors: Cep120 and TACCs control interkinetic nuclear migration. Neuron, 56 (1), 1-3.

Hayes, N. L., \& Nowakowski, R. S. (2000). Exploiting the dynamics of Sphase tracers in developing brain: Interkinetic nuclear migration for cells entering versus leaving the S-phase. Developmental Neuroscience, 22, 44-55.

Hochegger, H., Takeda, S., \& Hunt, T. (2008). Cyclin-dependent kinases and cell-cycle transitions: Does one fit all? Nature Reviews. Molecular Cell Biology, 9(11), 910-916.

Kadoshima, T., Sakaguchi, H., Nakano, T., Soen, M., Ando, S., Eiraku, M., \& Sasai, Y. (2013). Selforganization of axial polarity, inside-out layer pattern, and species-specific progenitor dynamics in human ES cellderived neocortex. Proceedings of the National Academy of Sciences of the United States of America, 110(50), 20284-20289.

Kill, I. R. (1996). Localisation of the Ki-67 antigen within the nucleolus. Evidence for a fibrillarindeficient region of the dense fibrillar component. Journal of Cell Science, 109(Pt 6), 1253-1263.

Kornack, D. R., \& Rakic, P. (1998). Changes in cell-cycle kinetics during the development and evolution of primate neocortex. Proceedings of the National Academy of Sciences of the United States of America, 95, 1242-1246.

Kosodo, Y., Suetsugu, T., Suda, M., Mimori-Kiyosue, Y., Toida, K., Baba, S. A., ... Matsuzaki, F. (2011). Regulation of interkinetic nuclear migration by cell cycle-coupled active and passive mechanisms in the developing brain. The EMBO Journal, 30(9), 1690-1704. 
Kubbutat, M. H., Key, G., Duchrow, M., Schluter, C., Flad, H. D., \& Gerdes, J. (1994). Epitope analysis of antibodies recognising the cell proliferation associated nuclear antigen previously defined by the antibody Ki-67 (Ki-67 protein). Journal of Clinical Pathology, 47(6), 524-528.

Lahne, M., Li, J., Marton, R. M., \& Hyde, D. R. (2015). Actin-cytoskeletonand rock-mediated INM are required for photoreceptor regeneration in the adult Zebrafish retina. The Journal of Neuroscience, 35(47), 15612-15634.

Lancaster, M. A., Renner, M., Martin, C. A., Wenzel, D., Bicknell, L. S., Hurles, M. E., ... Knoblich, J. A. (2013). Cerebral organoids model human brain development and microcephaly. Nature, 501(7467), 373-379.

Langman, J., \& Nelson, G. R. (1968). A radioautographic study of the development of the somite in the chick embryo. Journal of Embryology and Experimental Morphology, 19(2), 217-226.

Latasa, M. J., Cisneros, E., \& Frade, J. M. (2009). Cell cycle control of notch signaling and the functional regionalization of the neuroepithelium during vertebrate neurogenesis. The International Journal of Developmental Biology, 53(7), 895-908.

Lee, H. O., \& Norden, C. (2013). Mechanisms controlling arrangements and movements of nuclei in pseudostratified epithelia. Trends in Cell Biology, 23(3), 141-150.

Leonhardt, H., Rahn, H. P., Weinzierl, P., Sporbert, A., Cremer, T., Zink, D., \& Cardoso, M. C. (2000). Dynamics of DNA replication factories in living cells. The Journal of Cell Biology, 149(2), 271-280.

Leung, L., Klopper, A. V., Grill, S. W., Harris, W. A., \& Norden, C. (2011). Apical migration of nuclei during G2 is a prerequisite for all nuclear motion in zebrafish neuroepithelia. Development, 138(22), 5003-5013.

Lukaszewicz, A., Savatier, P., Cortay, V., Kennedy, H., \& Dehay, C. (2002). Contrasting effects of basic fibroblast growth factor and neurotrophin 3 on cell cycle kinetics of mouse cortical stem cells. The Journal of Neuroscience, 22(15), 6610-6622.

Malatesta, P., Hartfuss, E., \& Gotz, M. (2000). Isolation of radial glial cells by fluorescent-activated cell sorting reveals a neuronal lineage. Development, 127(24), 5253-5263.

Meyer, E. J., Ikmi, A., \& Gibson, M. C. (2011). Interkinetic nuclear migration is a broadly conserved feature of cell division in pseudostratified epithelia. Current Biology, 21(6), 485-491.

Miyama, S., Takahashi, T., Nowakowski, R. S., \& Caviness, V. S. (1997). A gradient in the duration of the G1 phase in the murine neocortical proliferative epithelium. Cerebral Cortex, 7(7), 678-689.

Miyata, T. (2008). Development of three-dimensional architecture of the neuroepithelium: Role of pseudostratification and cellular 'community. Development, Growth \& Differentiation, 50(Suppl 1), S105-S112.

Miyata, T., Kawaguchi, A., Okano, H., \& Ogawa, M. (2001). Asymmetric inheritance of radial glial fibers by cortical neurons. Neuron, 31(5), 727-741.

Miyata, T., Okamoto, M., Shinoda, T., \& Kawaguchi, A. (2015). Interkinetic nuclear migration generates and opposes ventricular-zone crowding: Insight into tissue mechanics. Frontiers in Cellular Neuroscience, 8(473).

Morin, X., Jaouen, F., \& Durbec, P. (2007). Control of planar divisions by the G-protein regulator LGN maintains progenitors in the chick neuroepithelium. Nature Neuroscience, 10(11), 1440-1448. 
Murciano, A., Zamora, J., Lopez-Sanchez, J., \& Frade, J. M. (2002). Interkinetic nuclear movement may provide spatial clues to the regulation of neurogenesis. Molecular and Cellular Neurosciences, 21(2), $285-300$.

Nasu, M., Takata, N., Danjo, T., Sakaguchi, H., Kadoshima, T., Futaki, S., ... Sasai, Y. (2012). Robust formation and maintenance of continuous stratified cortical neuroepithelium by laminin-containing matrix in mouse ES cell culture. PLoS One, 7(12), e53024.

Nguyen, L., Besson, A., Heng, J. I., Schuurmans, C., Teboul, L., Parras, C., ... Guillemot, F. (2006). p27kip1 independently promotes neuronal differentiation and migration in the cerebral cortex. Genes \& Development, 20(11), 1511-1524.

Noctor, S. C., Flint, A. C., Weissman, T. A., Dammerman, R. S., \& Kriegstein, A. R. (2001). Neurons derived from radial glial cells establish radial units in neocortex. Nature, 409(6821), 714-720.

Norden, C., Young, S., Link, B. A., \& Harris, W. A. (2009). Actomyosin is the main driver of interkinetic nuclear migration in the retina. Cell, 138(6), 1195-1208.

Okamoto, M., Shinoda, T., Kawaue, T., Nagasaka, A., \& Miyata, T. (2014). Ferret-mouse differences in interkinetic nuclear migration and cellular densification in the neocortical ventricular zone. Neuroscience Research, 83, 25-32.

Osumi, N., \& Inoue, T. (2001). Gene transfer into cultured mammalian embryos by electroporation. Electroporation Methods in Neuroscience, 24(1), 35-42.

Pearson, R. A., Luneborg, N. L., Becker, D. L., \& Mobbs, P. (2005). Gap junctions modulate interkinetic nuclear movement in retinal progenitor cells. The Journal of Neuroscience, 25(46), 10803-10814.

Pilaz, L. J., Patti, D., Marcy, G., Ollier, E., Pfister, S., Douglas, R. J., ... Dehay, C. (2009). Forced G1phase reduction alters mode of division, neuron number, and laminar phenotype in the cerebral cortex. Proceedings of the National Academy of Sciences of the United States of America, 106, 2192421929.

Polleux, F., Dehay, C., Moraillon, B., \& Kennedy, H. (1997). Regulation of neuroblast cell-cycle kinetics plays a crucial role in the generation of unique features of neocortical areas. The Journal of Neuroscience, 17 (20), 7763-7783.

Rakic, P. (1972). Mode of cell migration to the superficial layers of fetal monkey neocortex. The Journal of Comparative Neurology, 145, 61-84.

Roos, G., Landberg, G., Huff, J. P., Houghten, R., Takasaki, Y., \& Tan, E. M. (1993). Analysis of the epitopes of proliferating cell nuclear antigen recognized by monoclonal antibodies. Laboratory Investigation, 68(2), 204-210.

Sakaue-Sawano, A., Yo, M., Komatsu, N., Hiratsuka, T., Kogure, T., Hoshida, T., ... Miyawaki, A. (2017). Genetically encoded tools for optical dissection of the mammalian cell cycle. Molecular Cell, 68(3), 626-640 e625, 640.e5.

Sargeant, T. J., Day, D. J., Miller, J. H., \& Steel, R. W. (2008). Acute in utero morphine exposure slows $\mathrm{G} 2 / \mathrm{M}$ phase transition in radial glial and basal progenitor cells in the dorsal telencephalon of the E15.5 embryonic mouse. The European Journal of Neuroscience, 28(6), 1060-1067.

Sauer, F. C. (1935). Mitosis in the neural tube. The Journal of Comparative Neurology, 62, 377-405.

Sauer, M. E., \& Walker, B. E. (1959). Radioautographic study of interkinetic nuclear migration in the neural tube. Proceedings of the Society for Experimental Biology and Medicine, 101, 557-560. 
Schenk, J., Wilsch-Brauninger, M., Calegari, F., \& Huttner, W. B. (2009). Myosin II is required for interkinetic nuclear migration of neural progenitors. Proceedings of the National Academy of Sciences of the United States of America, 106(38), 16487-16492.

Schluter, C., Duchrow, M., Wohlenberg, C., Becker, M. H., Key, G., Flad, H. D., \& Gerdes, J. (1993). The cell proliferation-associated antigen of antibody Ki-67: A very large, ubiquitous nuclear protein with numerous repeated elements, representing a new kind of cell cycle maintaining proteins. The Journal of Cell Biology, 123(3), 513-522.

Smart, I. H., Dehay, C., Giroud, P., Berland, M., \& Kennedy, H. (2002). Unique morphological features of the proliferative zones and postmitotic compartments of the neural epithelium giving rise to striate and extrastriate cortex in the monkey. Cerebral Cortex, 12(1), 37-53.

Spear, P. C., \& Erickson, C. A. (2012). Interkinetic nuclear migration: A mysterious process in search of a function. Development, Growth \& Differentiation, 54(3), 306-316.

Starborg, M., Gell, K., Brundell, E., \& Hoog, C. (1996). The murine Ki-67 cell proliferation antigen accumulates in the nucleolar and heterochromatic regions of interphase cells and at the periphery of the mitotic chromosomes in a process essential for cell cycle progression. Journal of Cell Science, 109(Pt 1), 143-153.

Strzyz, P. J., Lee, H. O., Sidhaye, J., Weber, I. P., Leung, L. C., \& Norden, C. (2015). Interkinetic nuclear migration is centrosome independent and ensures apical cell division to maintain tissue integrity. Developmental Cell, 32(2), 203-219.

Sugiyama, M., Sakaue-Sawano, A., Iimura, T., Fukami, K., Kitaguchi, T., Kawakami, K., ... Miyawaki, A. (2009). Illuminating cell-cycle progression in the developing zebrafish embryo. Proceedings of the National Academy of Sciences of the United States of America, 106(49), 20812-20817.

Tabata, H., \& Nakajima, K. (2001). Efficient in utero gene transfer system to the developing mouse brain using electroporation: Visualization of neuronal migration in the developing cortex. Neuroscience, 103(4), 865-872.

Takei, N., \& Endo, Y. (1994). Ca2+ Ionophore-induced apoptosis on cultured embryonic rat corticalneurons. Brain Research, 652(1), 65-70.

Tamai, H., Shinohara, H., Miyata, T., Saito, K., Nishizawa, Y., Nomura, T., \& Osumi, N. (2007). Pax6 transcription factor is required for the interkinetic nuclear movement of neuroepithelial cells. Genes to Cells, 12(9), 983-996.

Taverna, E., \& Huttner, W. B. (2010). Neural progenitor nuclei IN motion. Neuron, 67(6), 906-914.

Tsai, J. W., Chen, Y., Kriegstein, A. R., \& Vallee, R. B. (2005). LIS1 RNA interference blocks neural stem cell division, morphogenesis, and motility at multiple stages. The Journal of Cell Biology, 170(6), 935-945.

Tsai, J. W., Lian, W. N., Kemal, S., Kriegstein, A. R., \& Vallee, R. B. (2010). Kinesin 3 and cytoplasmic dynein mediate interkinetic nuclear migration in neural stem cells. Nature Neuroscience, 13(12), $1463-1471$.

Ueno, M., Katayama, K., Yamauchi, H., Nakayama, H., \& Doi, K. (2006). Cell cycle progression is required for nuclear migration of neural progenitor cells. Brain Research, 1088(1), 57-67.

Waseem, N. H., \& Lane, D. P. (1990). Monoclonal antibody analysis of the proliferating cell nuclear antigen (PCNA). Structural conservation and the detection of a nucleolar form. Journal of Cell Science, 96(Pt 1), 121-129. 
Winking, H., Gerdes, J., \& Traut, W. (2004). Expression of the proliferation marker Ki-67 during early mouse development. Cytogenetic and Genome Research, 105(2-4), 251-256.

Wittelsberger, S. C., Kleene, K., \& Penman, S. (1981). Progressive loss of shape-responsive metabolic controls in cells with increasingly transformed phenotype. Cell, 24(3), 859-866.

Yamada, M., Udagawa, J., Hashimoto, R., Matsumoto, A., Hatta, T., \& Otani, H. (2013). Interkinetic nuclear migration during early development of midgut and ureteric epithelia. Anatomical Science International, 88(1), 31-37.

Zabaglo, L., Salter, J., Anderson, H., Quinn, E., Hills, M., Detre, S., ... Dowsett, M. (2010). Comparative validation of the SP6 antibody to Ki67 in breast cancer. Journal of Clinical Pathology, 63(9), 800 804. 


\section{Supporting information}

\section{Table S1: Primary antibodies}

\begin{tabular}{|c|c|c|c|c|c|}
\hline Antigen & Immunogen & $\begin{array}{l}\text { Manufacturer } \\
(\text { Catalog \#) }\end{array}$ & Species & Dilution & RRID \# \\
\hline GFP & $\begin{array}{l}\text { Directly from the jellyfish } \\
\text { Aequorea victoria }\end{array}$ & $\begin{array}{l}\text { Thermo Fisher } \\
\text { Scientific } \\
\text { (A10262) }\end{array}$ & Chicken & $1 / 800$ & AB_2534023 \\
\hline $\mathrm{Ki}-67$ & $\begin{array}{l}\text { Synthetic peptide derived from } \\
\text { the human Ki-67 protein, clone } \\
\text { SP6 - recognizes the same } \\
\text { epitope as MIB1: a repetitive 66- } \\
\text { bp element (FKEL and FKELF) }\end{array}$ & $\begin{array}{l}\text { Thermo Fisher } \\
\text { Scientific (MA5- } \\
\text { 14520) }\end{array}$ & Rabbit & $1 / 400$ & AB_10979488 \\
\hline PCNA & $\begin{array}{l}\text { pC2T construct, the rat cDNA for } \\
\text { PCNA was cloned into } \\
\text { expression vectors, clone PC10 }\end{array}$ & DAKO (M0879) & Mouse & $1 / 400$ & AB_2160651 \\
\hline
\end{tabular}




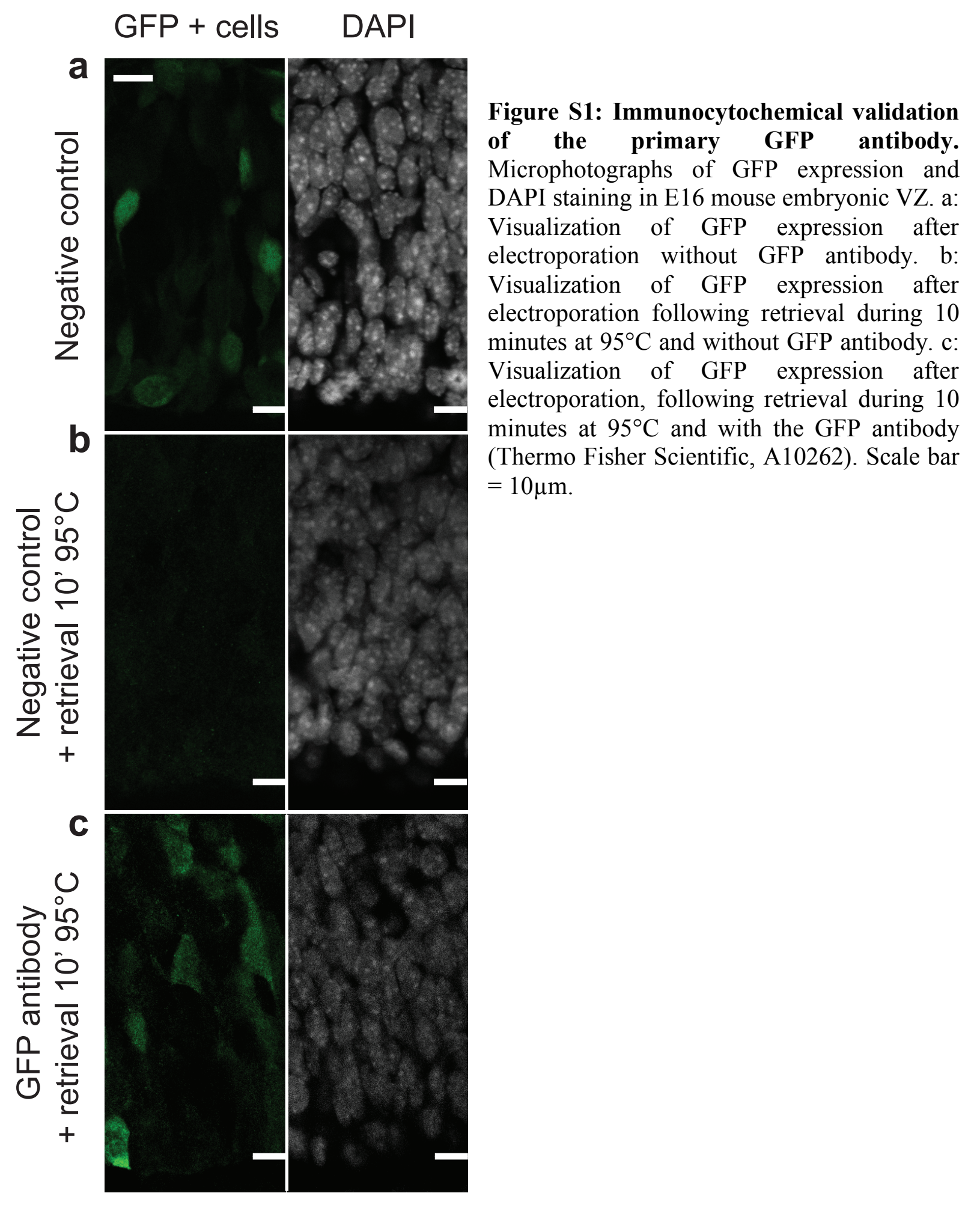

